\title{
Integrating Diffusion of Innovations and Theory of Planned Behavior to Predict Intention to Adopt Electric Vehicles
}

\author{
Sun Jung Moon ${ }^{1}$ \\ ${ }^{1}$ Research Professor of Business Administration, Kyungpook National University, Korea \\ Correspondence: Sun Jung Moon, Research Professor of Business Administration, Kyungpook National \\ University, Korea. E-mail: s2moon@knu.ac.kr
}

Received: August 24, 2020

doi:10.5539/ijbm.v15n11p88
Accepted: September 18, 2020

Online Published: October 20, 2020

URL: https://doi.org/10.5539/ijbm.v15n11p88

\begin{abstract}
Electric vehicles (EVs) are recognized as effective solutions to the global air pollution problem, attracting much attention from businesses, governments, and consumers. Despite the heightened interest, EV penetration rates remain low. This study thus focuses on consumers' evaluation of EV innovation to provide implications for promoting EV adoption by proposing a theoretical model that integrates the diffusion of innovations theory and the theory of planned behavior to examine the relationship between consumers' perceived innovation characteristics and the adoption of EVs; the study findings indicate that the evaluation of consumers' EV innovation has a significant impact on consumers' attitudes toward and intention for EV adoption. Several important innovation characteristics promote practical implications for spreading EV acceptance.
\end{abstract}

Keywords: electric vehicle, diffusion of innovations, theory of planned behavior, perceived innovation characteristics

\section{Introduction}

The world is facing environmental problems due to global warming and climate change caused by excessive use of fossil fuels. In the U.S., $>30 \%$ of total greenhouse gases are emitted from the transportation sector, of which $>60 \%$ are emitted by light-duty vehicles (U.S. Environmental Protection Agency, 2015). Gasoline-fueled vehicles and existing internal combustion engine vehicles are suggested to be the main culprit of environmental pollution (White \& Sintov, 2017).

Businesses and governments are aware of the seriousness of environmental pollution and strive to adopt new, preventive environmental technologies. Alternative fuel vehicles (AFVs) have been proposed as promising measures to resolve air pollution-related problems (White \& Sintov, 2017); among AFVs, the electric vehicle (EV) does not use fuel, operates a motor through batteries, and generates minimal exhaust gas, and hence, they are attracting attention with respect to solving the greenhouse gas-related problems. Several countries have initiated policies to stimulate the production and acceptance of EVs and reduce $\mathrm{CO}_{2}$ emissions to meet their sustainability goals (Brady \& O’Mahony, 2011; Rezvani et al., 2015).

To stimulate the EV market, the Korean government is implementing eco-friendly policies such as subsidies for EV purchases and tax reductions; despite the Korean government's efforts and the environmental improvement of EVs, the spread of EVs is very slow. However, the penetration rate of EVs increased steadily from 2011 to 2017, exceeding 10,000 units, but has decreased since 2018. Currently, the penetration rate of EVs is far below that of internal combustion engine vehicles (Korea Ministry of Environment, 2019). One of the interpretations for this aspect is the anxiety among consumers about the lack of EV-charging facilities and EVs' limited driving range, thereby implying that public acceptance of EVs depends on consumer perception (Schuitema et al., 2013); therefore, it is important to understand and tackle consumers' perceptions of EVs to promote its acceptance (Rezvani et al., 2015). Moreover, the performance (success or failure) of an innovative product is determined by consumers' evaluations of the product's innovation and acceptance of the product (Olshavsky \& Spreng, 1996). Companies should pay more attention to product innovations as evaluated by consumers. Therefore, to stimulate EV demand, studies on the relationship between consumer evaluation and acceptance of EVs are required, alongside the development of effective marketing strategies.

In recent years, several studies on the acceptance of EVs have been conducted that primarily focused on 
examining the relationships between factors affecting EV acceptance and purchase intention (Delang \& Cheng, 2012; Egbue \& Long, 2012; Hidrue et al., 2011; Morton et al., 2016; Orlov \& Kallbekken, 2019; White \& Sintov, 2017) and reviewing the current state of the EV market (Egbue \& Long, 2012; Heffner et al., 2007; Larson et al., 2014; Plötz et al., 2014). However, these studies did not consider the evaluation of EVs from consumers' perspective (Jansson, 2011), and few attempts have been made to understand consumer perceptions based on theoretical models of consumer behavior. To address this gap, this study proposes a theoretical model integrating theory of planned behavior (TPB) (Ajzen, 1991) and diffusion of innovations (DOI) theory (Rogers, 2003) to examine the relationship between consumers' evaluation of innovativeness for EVs and the adoption of EVs.

TPB has been widely applied in various domains to predict human behavior and intentions and postulates that human behavioral intention is formed by three determining factors: attitude toward the behavior, subjective norm, and perceived behavioral control (PBC) (Ajzen, 1991). Thus, these three determinants can be used effectively to explain and predict intention to adopt EVs. EVs are recognized as eco-innovations because of their potential to reduce transportation sector's environmental problems; thus, they are regarded as the innovation acceptance behavior (Jansson, 2011; Liao et al., 2017). DOI provides a useful framework for studying the success of eco-innovations from the consumers' perspectives and aids in explaining as to why marketing strategies have varying impacts on eco-innovation success (Driessen \& Hillebrand, 2002). This theory identifies five innovation characteristics: relative advantage, compatibility, complexity, observability, and trialability; they are subjected to the perception of potential adopters (Driessen \& Hillebrand, 2002) and can be used as indicators by the TPB model to improve the prediction of EV adoption. In this context, this study proposes a DOI-TPB integration model to better determine the adoption of EVs when analyzing the perceived innovation characteristics (PICs) of EVs on the attitude toward and acceptance of EVs.

As marketers strive to study consumer perceptions of new technological innovations to predict consumer behaviors and reactions (Rogers, 2003), the study results will help in explaining EV adoption decisions and provide useful implications for marketing strategies to promote EV adoption.

\section{Theoretical Background}

\section{$2.1 T P B$}

TPB has been employed to elucidate social behaviors in diverse settings, including consumer behaviors, and has proved its usefulness with long-accumulated empirical research (Zhou et al., 2013); it is an extension of Fishbein and Ajzen's (1975) theory of reasoned action (TRA), which predicts an individual's behavioral intention by attitude toward behavior and subjective norm. TPB adds PBC to the previous TRA model to overcome the limitations of TRA such as situations where people's volitional control is incomplete (Ajzen, 1991). When people require information, skills, opportunities, and other resources to perform a behavior, they perceive barriers and obstacles depending on the availability of the required resources. Under these circumstances, the TPB, which accounts for the ease and difficulty of carrying out the behavior, is more appropriate (Hansen, 2008). PBC needs to be considered in predicting EV adoption, as it requires not only internal resources such as individual abilities and self-efficacy but also external resources such as opportunities and information; it also constitutes the effects of social impact, a variable traditionally associated with DOI (Crespo \& del Bosque, 2008; Liao et al., 2017).

According to TPB, individual behavior is assumed to be the result of behavioral intention, and behavioral intention is formed by behavioral attitude, subjective norm, and PBC (Ajzen, 1991). Attitude is a latent disposition or tendency that an individual has about a particular behavior and refers to the degree to which a person evaluates the outcome of that behavior either positively or negatively. Sutcliffe et al. (2008) and De Groot and Steg (2007) argued that attitude toward products has a positive effect on consumers' intentions to use them. Crespo and del Bosque (2008), Fang et al. (2009), and Yang (2012) analyzed the relationship between user attitude and intention to adopt web technologies; all of these studies reveal that attitude has a significant impact on intention. On the basis of the previous studies, the relationship between attitude toward EV adoption and intention to adopt EVs is hypothesized as in the following manner:

H1. Attitude toward EV adoption is positively related to intention to adopt EVs.

Subjective norm refers to the social pressures that influence an individual whether or not to perform a particular behavior and is related to the acceptance of such social pressure to perform the behavior in a particular way. It can be defined as an individual's perception of what important referents such as family members or friends expect the individual to do (Adnan et al., 2017), making it an important variable that significantly influences behavioral intention (Chen \& Tung, 2014; Han et al., 2010; Hansen, 2008, Lowe \& Alpert, 2015). Bockarjova and Steg (2014) and Chen and Tung (2014) argued that high social pressures from those who expect an 
individual to perform a particular behavior increase the individual's intention to perform it; therefore, subjective norm is hypothesized to have a positive effect on intention to adopt EVs.

H2. Subjective norm is positively related to the intention to adopt EVs.

PBC refers to an individual's belief about how easy or difficult it is to perform a particular behavior (Ajzen, 1991). It particularly relates to an individual's internal (e.g., self-efficacy, confidence, or ability) and external (e.g., economic conditions or time) resources to perform a specific behavior (Taylor \& Todd, 1995). If an individual assesses that he or she has sufficient resources or competencies to perform a particular behavior, then the individual perceives fewer difficulties in performing it. López-Mosquera and Sánchez (2012) reported that the higher the level of consumers' behavioral control, the higher the behavioral intention. Therefore, it is hypothesized that $\mathrm{PBC}$ has a positive effect on intention to adopt EVs.

H3. $\mathrm{PBC}$ is positively related to the intention to adopt EVs.

\section{$2.2 \mathrm{DOI}$}

As consumer acceptance of innovative products, ideas, and practices are crucial for triggering DOI, adoption and diffusion of innovations have received much attention in marketing and consumer literature (Jansson, 2011). Rogers's (2003) DOI theory has been widely used to explain and predict consumer behaviors related to innovation adoption (Chou et al., 2012). According to DOI, the innovation-decision process has five stages: (1) initial knowledge of the innovation, (2) persuasion by forming a favorable attitude, (3) decision to adopt the innovation, (4) implementation by using the innovation, and (5) confirmation and continuous use of the innovation (Rogers, 2003). The first two steps are important for understanding consumer adoption behavior of innovation because attitude toward innovation is developed. In this attitude forming process of innovation, potential adopters' personality traits, particularly their innovativeness, and their perceptions of the characteristics of the innovation will play an important role (Jansson, 2011).

On the basis of these findings, this study and others focus on the relationship between consumers' PICs of EVs and intention to adopt EVs with a proposed DOI-TPB integration model. Marcati et al. (2008) proposed an integrated framework to improve the prediction of entrepreneurs' intention to adopt innovation, and Chou et al. (2012) used a similar approach in analyzing the adoption of green practices in the restaurant industry. Jackson et al. (2013) used a DOI-TPB integration model to predict intention to adopt technological innovation. This study attempts to integrate the five PICs proposed by Rogers (2003) with TPB to better explain EV adoption decisions and is the first attempt to apply a DOI-TPB integration model at the consumer level, in contrast to previous organization-level studies.

DOI assumes that potential adopters form their attitudes toward innovation centered on their perceptions of the five PICs (Jansson, 2011): relative advantage, compatibility, complexity, trialability, and observability. Chou et al. (2012) claimed that PICs capture approximately $49 \%-87 \%$ of the variance of innovation adoption. Specific descriptions of PICs are given below (Adnan et al., 2017; Chou et al., 2012; Rogers, 2003).

(1) Relative advantage is the extent to which innovation is perceived to be superior to existing products or ideas (Rogers, 2003). The level of added value of an innovative product is determined by its relative economic, social, and technical advantages compared with the existing products, spurring rapid adoption and diffusion. In the case of EV adoption, innovation cost and motivation for social status are anticipated to operate as essential relative advantage factors. Innovators, early adopters, and early majority are more likely to be motivated by these factors. (2) Compatibility is the extent to which innovative products are perceived to be consistent with consumer needs, beliefs, values, and experiences (Rogers, 2003). As innovation is more meaningful to potential consumers and more compatible with their existing behavioral patterns and experiences, innovation adoption is more likely. In contrast, if innovation differs from the requirements of the consumers and lacks compatibility, it negatively affects adoption (McKenzie, 2001). In several DOI studies, relative advantages and compatibility are considered conceptually different but similar. Holak and Lehmann (1990) argued that relative advantage and compatibility, among the five PICs, have the most significant impact on innovation adoption. (3) Complexity is the extent to which innovative products are perceived as hard to understand and use (Rogers, 2003). This characteristic is related to the problems arising when using the innovative product, thus implying that complexity has a negative correlation with the adoption of innovative products. On the contrary, if innovations are user-friendly, then they can be successfully adopted (Martin, 2003). (4) Observability, often referred to as visibility, is defined as the extent to which results of adopting an innovative product are visible to others (Rogers, 2003). Peer observation is a key motivator for the adoption and diffusion of innovation (Parisot, 1997). Frequent exposure of an innovative product to potential consumers increases familiarity, spreads word-of-mouth, and accelerates the adoption and diffusion process. (5) Trialability is the ease with which potential consumers can try an innovative product. 
Innovative products with high trialability are more quickly adopted in the market. Furthermore, innovations can be altered or modified while potential consumers are trying the product, leading to reinvention. This aspect further improves innovation and facilitates and accelerates adoption. According to Rogers (2003), trialability is an important factor for later adopters who deliberately embrace innovation. It can be enhanced by providing potential consumers with information for verification or allowing adaptive tests. Providing test-driving opportunities for EVs increases perceived trialability, thereby enhancing EV adoption.

Several studies suggested that PICs have a direct impact on innovation adoption (Agarwal \& Prasad, 1997; Damanpour \& Schneider, 2009; Hebert \& Benbasat, 1994). However, Chou et al. (2012) argued that PICs can be modeled more effectively by assuming that they affect innovation adoption indirectly with the mediation of attitude, as PICs are cognitive indicators of attitude toward innovation adoption. Rogers (2003) asserted that the formation of a specific attitude toward innovation is a major factor influencing the decision process related to adoption of the innovation. Attitude predicts consumption behavior better than other factors (Brunsø et al., 2004); it mediates the influences and stimuli of external variables on behavioral intention and thus varies according to the area of consumption (Frambach \& Schillewaert, 2002). Thus, attitude represents context-specific dispositions in which an individual's perception is linked to actual consumption behaviors (Jansson et al., 2017). Therefore, PICs more effectively predict adoption intention when mediated through attitude.

Putzer and Park (2012) found that PICs are a significant antecedent variable of attitude toward emerging mobile technologies. Lowe and Alpert (2015) found that consumer perception of innovativeness has a positive effect on attitude. In a study on the adoption of AFVs, Jansson (2011) noted that the adopters perceive AFVs as more advantageous, compatible, observable, and less complex than the non-adopters. Smerecnik and Andersen (2011) revealed that relative advantage and complexity are related to the sustainability of innovation in hotels and ski resorts. Chou et al. (2012) examined the effect of four PIC variables (relative advantage, compatibility, complexity, and observability) on attitude toward adopting green practices in the restaurant industry.

On the basis of previous research, this study postulates that because consumers perceive EVs as having an advantage over existing vehicles, consumer attitude toward EV adoption will be more positive.

H4. Relative advantage is positively related to attitude toward EVs.

H5. Compatibility is positively related to attitude toward EVs.

H6. Complexity is negatively related to attitude toward EVs.

H7. Observability is positively related to attitude toward EVs.

H8. Trialability is positively related to attitude toward EVs.

\subsubsection{Consumer Innovativeness}

Consumer innovativeness is a key concept in DOI along with PICs (Rogers, 2003). It refers to the inherent and reveals the propensity of a consumer to adopt innovative products, whereas PICs represent perceptions of consumers of the innovative nature of products. Consumer innovativeness is the degree to which an individual adopts technologies in a relatively early stage, prior to adoption by others (Rogers, 2003). Consumer innovativeness has played an important role in understanding the early adoption behaviors of consumers particularly because it reflects desires of early adopters who have less antipathy to innovative technologies and want to purchase innovative products (Bartels \& Reinders, 2011; Morton et al., 2016; Roehrich, 2004).

Although consumer innovativeness and evaluation of product innovativeness are different concepts, several studies identify a linkage between them(Lu et al., 2005; Venkatesh et al., 2003). Jackson et al. (2013) verified that consumers' perceived product evaluations vary according to their innovativeness, i.e., the higher the consumer innovativeness, the more likely consumers are to perceive product innovation positively. Yang (2012) examined the moderating effects of consumer innovativeness in the relationship between consumer product evaluation and attitude toward mobile shopping. These findings imply that consumer innovativeness can have a moderating influence on the relationship between PICs and attitude toward innovation adoption.

As consumers with higher innovativeness are more likely to adopt new innovative products and gain experiences by using varied innovative products, they are more confident in their evaluation of product innovativeness; therefore, consumers with higher innovativeness are expected to reinforce their attitudes toward EV adoption. Hypotheses about the moderating effects of consumer innovativeness are given below:

H9 (a). Consumer innovativeness moderates the relationship between relative advantage and attitude toward EV adoption.

H9 (b). Consumer innovativeness moderates the relationship between compatibility and attitude toward EV 
adoption.

H9 (c). Consumer innovativeness moderates the relationship between complexity and attitude toward EV adoption.

H9 (d). Consumer innovativeness moderates the relationship between observability and attitude toward EV adoption.

H9 (e). Consumer innovativeness moderates the relationship between trialability and attitude toward EV adoption.

\subsection{Moderating Effects of Demographic Characteristics}

TPB defines the factors that directly influence behavioral intention but is sufficiently flexible in allowing for the inclusion of regulatory variables in its relationships. According to previous studies, the influence of antecedent variables of behavioral intention is either strong or weak, depending on the situation and individual characteristics (Ajzen, 1988; Keith \& McWilliams, 1999; Van Hooft et al., 2005). De Groot and Steg (2007) argued that the relative importance of attitude, subjective norm, and PBC differ among the target groups, and these differences inhibit general conclusions about behavioral prediction.

Several empirical studies that analyzed the differences in innovation adoption by demographic variables are inconclusive or conflicting (White \& Sintov, 2017). According to surveys on EVs, younger people are generally more interested and have a higher intention to purchase EVs. Hyundai Motor's survey of 748 electric car buyers in 2016 found that people in their 20s-30s exceed $40 \%$ of the total market share (Kim, 2016). Hyundai Motor believed that the survey results indicated that young people have less fear of new things and are more innovative than their older counterparts. In contrast, Plötz et al. (2014) demonstrated that the proportion of consumers who used or intended to use EVs was the highest for consumers in their 40s and the lowest for consumers in their 20s. Consequently, existing literature does not provide consistent predictions on EV adoption among different age groups.

This study includes age as a moderator between intention of EV adoption and three direct antecedents of intention to examine the relationships among key variables of TPB across different age groups. The hypotheses to examine the moderating effect of age on the relationship between the key variables of TPB are given below:

H10 (a). Age moderates the relationship between attitude and intention to adopt EVs.

H10 (b). Age moderates the relationship between social norm and intention to adopt EVs.

H10 (c). Age moderates the relationship between $P B C$ and intention to adopt EVs.

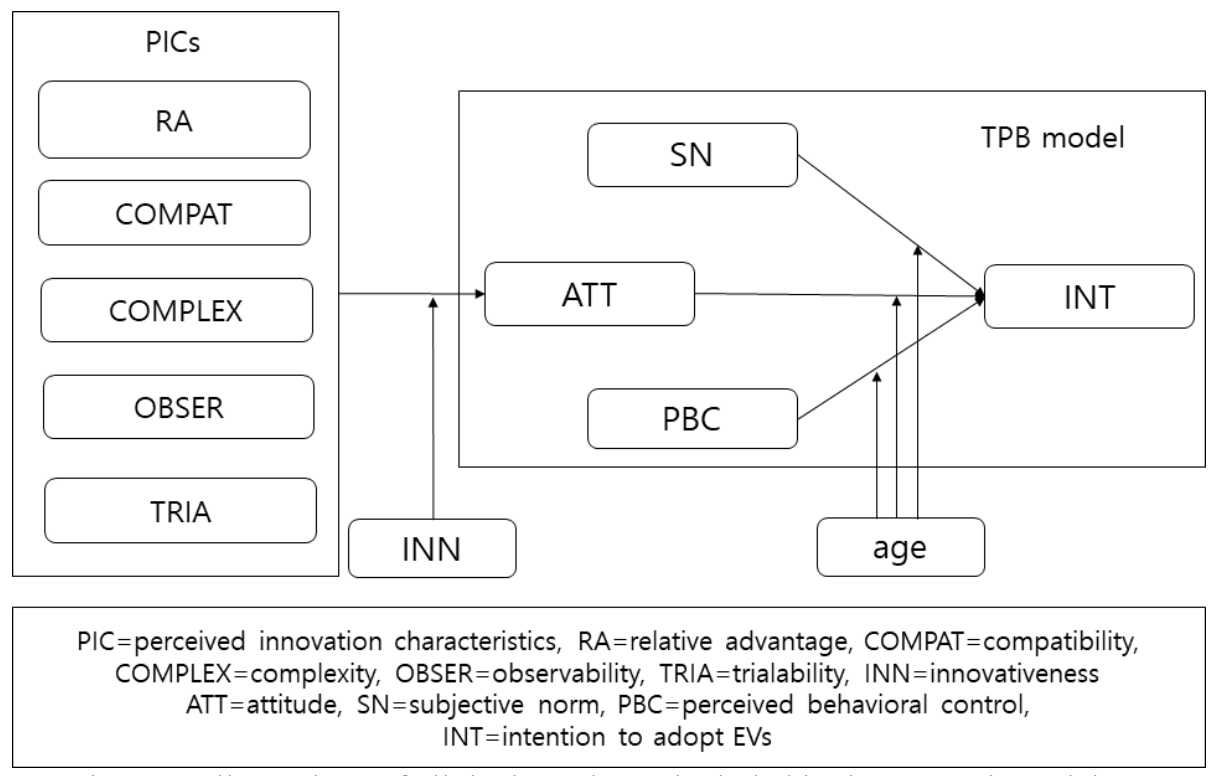

Figure 1. Illustrations of all the hypotheses included in the research model 


\section{Methodology}

\subsection{Participants and Procedure}

This study surveyed potential EV consumers above the age of 25 years residing in Daegu and Gyeongbuk province, Korea, using a convenience sampling method. The survey questionnaire was constructed and distributed using a Google survey form and collected from voluntary respondents through a mobile social network. Data were collected for one month, i.e., from June 1 to 30, 2019, from a total of 176 respondents. Structural equation modeling (SEM) was employed for data analysis. Among SEM techniques, this study used partial least squares (PLS) SEM, which is considered more appropriate than covariance-based SEM when a model is complex with many constructs and the sample size is relatively small. In a PLS-SEM analysis, the "10-times rule" is frequently used as a barometer for estimating the minimum sample size required. The rule simply states that the sample size should be the larger of the following two values, (1) the maximum number of formative indicators of a variable multiplied by 10 and (2) the maximum number of structural paths directed to a variable multiplied by 10 (Hair et al., 2017). The collected data were further analyzed using IBM SPSS Statistics 22.0 (SPSS), and SmartPLS 3.0. SPSS was used to obtain descriptive statistics including frequency analysis; SmartPLS 3.0 was also used to verify the relationships among constructs in the SEM model. The analysis of the PLS-SEM model in this study was performed based on the procedures and criteria presented by Hair et al. (2017).

\subsection{Measures}

Appendix 1 exhibits all the questionnaire items. The questionnaire survey was measured on a 5-point Likert scale, ranging from "very unlikely" (1) to "very likely" (5). All measurement items were adopted from previous research in which their validity and reliability were established.

PICs include five dimensions, and the measurement items were constructed based on Jansson (2011). PICs were measured using 17 items: 4 for relative advantage, 3 for compatibility, 4 for complexity, 3 for trialability, and 3 for observability. Measurements of attitude, subjective norm, PBC, and intention included in TPB are based on the TPB questionnaire presented by Ajzen (2019). The PBC items in the TPB model were constructed based on Wang et al. (2016) and Yadav et al. (2019). Attitude toward behavior was measured by 4 items, subjective norm by 3 items, PBC by 3 items, and intention by 3 items. Finally, the measurement of consumer innovativeness was constructed based on Lu et al. (2005) and consisted of 4 items.

\section{Results}

\subsection{Demographic Profile and Measurement Model}

The demographic characteristics of the sample are illustrated in this section. The 176 respondents were equally distributed gender wise, i.e., 88 men (50\%) and 88 women $(50 \%) ; 34(19.3 \%)$ were in their 20s (23-29 years), $96(54.5 \%)$ in their $30 \mathrm{~s}$ (30-39 years), $26(14.8 \%)$ in their $40 \mathrm{~s}(40-49$ years), $17(9.7 \%)$ in their 50 s $(50-59$ years), and $3(1.7 \%)$ in their $60 \mathrm{~s}(\geq 60$ years). By marital status, $66(37.5 \%)$ are single and $110(62.5 \%)$ are married. In terms of monthly income, 5 (2.8\%) earn less than $\$ 1$ million (US\$860), 34 (19.3\%) earn \#1-3 million (US\$860-2580), 60 (34.1\%) earn $\$ 3-5$ million (US\$2580-4300), and 77 (43.8\%) earn more than $\$ 5$ million (US\$4300).

For the analysis of the structural model to be meaningful, the reliability and validity of all indicators must be secured and the collinearity problem between these variables must be resolved. The analysis results for the reliability of the measurement model are presented in Table 1. 
Table 1 . Reliability and validity measurements

\begin{tabular}{|c|c|c|c|c|c|}
\hline \multirow[t]{2}{*}{ Construct } & Indicators & Loadings & $\begin{array}{l}\text { Indicator } \\
\text { reliability }\end{array}$ & Cronbach's alpha & AVE \\
\hline & Judgment criteria: & $>0.70$ & $>0.50$ & $>0.60$ & $>0.50$ \\
\hline \multirow{4}{*}{ RA } & RA1 & 0.687 & 0.472 & \multirow{4}{*}{0.742} & \multirow{4}{*}{0.564} \\
\hline & RA2 & 0.814 & 0.663 & & \\
\hline & RA3 & 0.711 & 0.506 & & \\
\hline & RA4 & 0.785 & 0.616 & & \\
\hline \multirow{3}{*}{ COMPAT } & COMPAT1 & 0.875 & 0.766 & \multirow{3}{*}{0.695} & \multirow{3}{*}{0.626} \\
\hline & COMPAT2 & 0.590 & 0.348 & & \\
\hline & COMPTA3 & 0.875 & 0.766 & & \\
\hline \multirow{4}{*}{ COMPLEX } & COMPLEX1 & -0.060 & 0.004 & \multirow{4}{*}{0.753} & \multirow{4}{*}{0.212} \\
\hline & COMPLEX2 & 0.435 & 0.189 & & \\
\hline & COMPLEX3 & 0.090 & 0.008 & & \\
\hline & COMPLEX4 & 0.804 & 0.646 & & \\
\hline \multirow{3}{*}{ OBS } & OBS1 & 0.881 & 0.776 & \multirow{3}{*}{0.766} & \multirow{3}{*}{0.662} \\
\hline & OBS2 & 0.802 & 0.643 & & \\
\hline & OBS3 & 0.753 & 0.567 & & \\
\hline \multirow{3}{*}{ TRIA } & TRIA1 & 0.806 & 0.650 & \multirow{3}{*}{0.822} & \multirow{3}{*}{0.733} \\
\hline & TRIA2 & 0.903 & 0.815 & & \\
\hline & TRIA3 & 0.858 & 0.736 & & \\
\hline \multirow{4}{*}{ INN } & INN1 & 0.949 & 0.900 & \multirow{4}{*}{0.962} & \multirow{4}{*}{0.897} \\
\hline & INN2 & 0.937 & 0.878 & & \\
\hline & INN3 & 0.963 & 0.927 & & \\
\hline & INN4 & 0.940 & 0.884 & & \\
\hline \multirow{4}{*}{ ATT } & ATT1 & 0.891 & 0.794 & \multirow{4}{*}{0.914} & \multirow{4}{*}{0.795} \\
\hline & ATT2 & 0.900 & 0.810 & & \\
\hline & ATT3 & 0.846 & 0.716 & & \\
\hline & ATT4 & 0.928 & 0.861 & & \\
\hline \multirow{3}{*}{ SN } & SN1 & 0.918 & 0.843 & \multirow{3}{*}{0.918} & \multirow{3}{*}{0.858} \\
\hline & $\mathrm{SN} 2$ & 0.933 & 0.870 & & \\
\hline & SN3 & 0.929 & 0.863 & & \\
\hline \multirow{3}{*}{$\mathrm{PBC}$} & $\mathrm{PBC} 1$ & 0.938 & 0.880 & \multirow{3}{*}{0.918} & \multirow{3}{*}{0.860} \\
\hline & $\mathrm{PBC} 2$ & 0.943 & 0.889 & & \\
\hline & $\mathrm{PBC} 3$ & 0.900 & 0.810 & & \\
\hline & INT1 & 0.981 & 0.962 & & \\
\hline INT & INT2 & 0.959 & 0.920 & 0.971 & 0.945 \\
\hline & INT3 & 0.977 & 0.955 & & \\
\hline
\end{tabular}


Table 2. Results for discriminant validity

\begin{tabular}{|c|c|c|c|c|c|c|c|c|c|c|}
\hline & RA & COMPAT & COMPLEX & OBSER & TRIA & INN & ATT & $\mathrm{SN}$ & PBC & INT \\
\hline RA & 0.751 & & & & & & & & & \\
\hline COMPAT & 0.573 & 0.791 & & & & & & & & \\
\hline COMPLEX & -0.056 & -0.144 & 0.827 & & & & & & & \\
\hline OBSER & 0.520 & 0.408 & -0.096 & 0.813 & & & & & & \\
\hline TRIA & 0.226 & 0.112 & -0.190 & 0.408 & 0.856 & & & & & \\
\hline INN & 0.456 & 0.556 & 0.073 & 0.381 & 0.016 & 0.947 & & & & \\
\hline ATT & 0.598 & 0.684 & -0.069 & 0.460 & 0.159 & 0.591 & 0.892 & & & \\
\hline $\mathrm{SN}$ & 0.578 & 0.622 & -0.120 & 0.479 & 0.171 & 0.686 & 0.707 & 0.927 & & \\
\hline PBC & 0.460 & 0.404 & 0.040 & 0.317 & 0.063 & 0.666 & 0.542 & 0.525 & 0.927 & \\
\hline INT & 0.522 & 0.642 & -0.096 & 0.418 & 0.160 & 0.822 & 0.735 & 0.812 & 0.615 & 0.972 \\
\hline
\end{tabular}

Note. The diagonal line is the $\sqrt{A V E}$ of each construct

First, composite reliability values are presented in Table 1; overall, the measurement model seems to have internal consistency reliability except for several indicators. Indicators RA1 and COMPAT2 were slightly below the criteria value, but they were included in the model, as the deviations were less. In contrast, indicators COMPLEX1 and COMPLEX3 were excluded from the analysis because their reliability measures were far below the criteria values. After excluding both the items, the complexity construct satisfied the judging criteria with a Cronbach's alpha of 0.640, and an average variance (AVE) of 0.626 was extracted.

Further, discriminant validity among constructs was analyzed, and the results are presented in Table 2. The correlation coefficient is smaller than the square root of the AVE, which confirms discriminant validity among the model constructs. The collinearity problem among constructs was examined, and the results are presented in Table 3, confirming no collinearity problem.

Table 3. Results for collinearity analysis

\begin{tabular}{lll}
\hline Construct & Tolerance $>0.2$ & VIF $<5$ \\
\hline Relative advantage & 0.596 & 1.756 \\
Compatibility & 0.637 & 1.570 \\
Complexity & 0.944 & 1.059 \\
Observability & 0.621 & 1.611 \\
Triability & 0.802 & 1.248 \\
Attitude & 0.459 & 2.177 \\
Subjective norm & 0.666 & 1.502 \\
Perceived behavioral control & 0.471 & 2.122 \\
\hline
\end{tabular}

\subsection{Structural Model and Test of Hypotheses}

The SEM analysis results for the integration model of EV adoption are presented in Figure 2. The values on the arrows between the latent variables are the path coefficients, and the values indicated on the arrows between the measured indicators and the latent variables represent the outer loadings. The numbers in the circle are the coefficients of determination $\left(\mathrm{R}^{2}\right.$ value), representing the variance of the construct explained by other variables, of which $0.75,0.50$, or 0.25 for latent variables can be described as substantial, moderate, or weak (Hair et al., 2017). In this study, the coefficient of determination for EV adoption was 0.734 , which indicates that the explanatory power of the model is very high. 


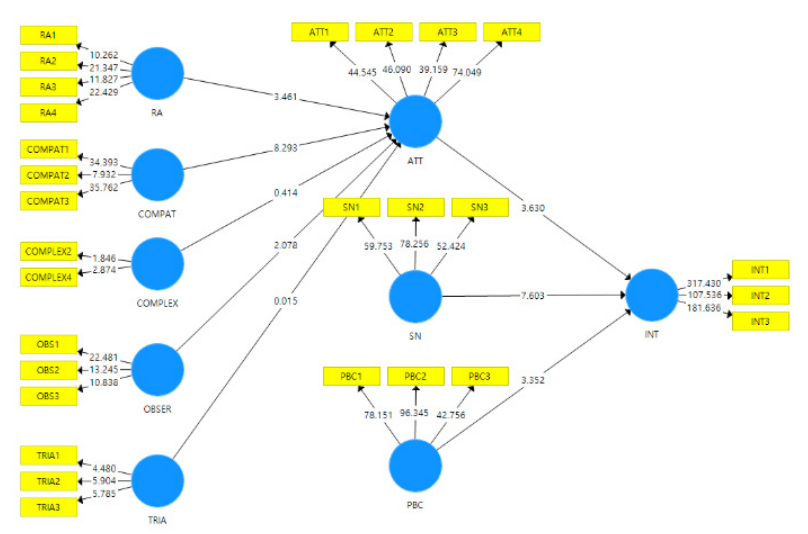

Figure 2. Results of path analysis of consumers' intention to adopt electric vehicles

To evaluate the significance of the path coefficient in the structural model of this study, the SmartPLS bootstrapping technique was applied. The results, presented in Table 4, indicate that all three determinants of the TPB model have significant effects on the intention for EV adoption, in order of subjective norm, attitude, and PBC. Thus, H1, H2, and $\mathrm{H} 3$ are all accepted.

Among the five characteristics of PICs, compatibility, relative advantage, and observability have a significant influence on attitude toward EVs, whereas complexity and trialability have no effect. Thus, H4, H5, and H7 are accepted, but $\mathrm{H} 6$ and $\mathrm{H} 8$ are rejected

Table 4. Significance testing results of path coefficients

\begin{tabular}{llllll}
\hline Hypothesis & Path coefficients & t-value & p-value & Significance \\
\hline RA $\rightarrow$ ATT & 0.249 & 3.398 & 0.001 & $* * *$ \\
COMPAT $\rightarrow$ ATT & 0.492 & 8.150 & 0.000 & $* * *$ \\
COMPLEX $\rightarrow$ ATT & 0.028 & 0.430 & 0.667 & NS \\
OBSER $\rightarrow$ ATT & 0.133 & 2.069 & 0.039 & $* *$ \\
TRIA $\rightarrow$ ATT & -0.001 & 0.015 & 0.988 & NS \\
ATT $\rightarrow$ INT & 0.252 & 3.813 & 0.000 & $* * *$ \\
SN $\rightarrow$ INT & 0.529 & 8.291 & 0.000 & $* * *$ \\
PBC $\rightarrow$ INT & 0.201 & 3.369 & 0.001 & $* * *$ \\
\hline
\end{tabular}

Note. $* \mathrm{p}<.1, * * \mathrm{p}<.05, * * * \mathrm{p}<.01, \mathrm{NS}:$ not significant.

To analyze the moderating effects of consumer innovativeness on the relationships between PICs and attitude toward EV adoption, the SmartPLS bootstrapping procedure was applied, and the results are summarized in Table 5. The sample was divided into two groups based on the median value of innovativeness scores resulting in a higher innovativeness group ( $>3$ points) of 102 respondents and a lower innovativeness group $(\leq 3$ points) of 74 respondents. The results of the difference analysis between the path coefficients of the two groups demonstrate that the level of innovativeness has a moderating effect on the relationships between relative advantage and attitude and between compatibility and attitude at a 5\% significance level. Thus, H9 (a) and H9 (b) are supported. However, the relationship between compatibility and attitude is strengthened at the higher level of innovativeness, while the relationship between relative advantage and attitude is strengthened at the lower level. As respondents in the higher innovativeness group evaluate EV adoption more favorably, they perceive compatibility of EV adoption more positively, while respondents in the lower innovativeness group evaluate EV adoption more positively, they perceive the relative advantage of EV more favorably. The results indicate that compatibility affects attitude more for those with more innovativeness, while relative advantages affects attitude for those with less innovativeness. 
Table 5. Results for moderation of innovativeness : Welch-Satterthwait Test

\begin{tabular}{lllllllll}
\hline & \multicolumn{2}{c}{ Group_high INN } & \multicolumn{2}{c}{ Group_low INN } & \multicolumn{2}{c}{ Group_high INN vs. Group_low INN } \\
& $p^{(1)}$ & $s e^{(1)}$ & $p^{(2)}$ & $s e^{(2)}$ & $\left|p^{(1)}-p^{(2)}\right|$ & t value & p value & significance \\
\hline RA $\rightarrow$ ATT & 0.122 & 0.092 & 0.413 & 0.095 & 0.290 & 2.210 & 0.030 & $* *$ \\
COMPAT $\rightarrow$ ATT & 0.568 & 0.075 & 0.273 & 0.106 & 0.296 & 2.283 & 0.025 & $* *$ \\
COMPLEX $\rightarrow$ ATT & 0.043 & 0.085 & 0.078 & 0.132 & 0.035 & 0.226 & 0.822 & NS \\
OBSER $\rightarrow$ ATT & 0.141 & 0.090 & 0.119 & 0.121 & 0.022 & 0.144 & 0.886 & NS \\
TRIA $\rightarrow$ ATT & 0.008 & 0.073 & 0.043 & 0.099 & 0.035 & 0.284 & 0.777 & NS \\
\hline
\end{tabular}

Note. $\mathrm{p}^{(1)}$ and $\mathrm{p}^{(2)}$ are path coefficients for Groups 1 and 2, respectively.

$\mathrm{se}^{(1)}$ and $\mathrm{se}^{(2)}$ are standard errors of $\mathrm{p}^{(1)}$ and, $\mathrm{p}^{(2)}$, respectively.

$* \mathrm{p}<.1, * * \mathrm{p}<.05, * * * \mathrm{p}<.01, \mathrm{NS}$ : not significant.

Next, the moderating effect of age on the relationships among the three determinants of TPB and intention for EV adoption was analyzed, and the results are summarized in Table 6. The moderating effect of age is not obvious when the sample is divided into five age groups from 20 s to 60 s. However, when the sample is divided into two age groups (younger: 20s-30s and older: 40s-60s), the analysis for path coefficient differences reveals several moderating effects. The results demonstrate that the relationship between attitude and intention is further strengthened in the younger age group, while the relationship between subjective norm and intention is stronger in the older age group. This implies that older people are more likely to be influenced by people of similar status or social groups when they consider EV adoption, and that, for younger people, attitude toward EV adoption is the critical determining factor. Thus, H10 (a) and H10 (b) are supported.

Table 6. Results for moderation of age: Welch-Satterthwait Test

\begin{tabular}{lllllllll}
\hline & \multicolumn{2}{c}{ Group_older } & \multicolumn{2}{c}{ Group_younger } & \multicolumn{2}{c}{ Group_older vs. Group_younger } \\
& $p^{(1)}$ & $s e^{(1)}$ & $p^{(2)}$ & $s e^{(2)}$ & $\left|p^{(1)}-p^{(2)}\right|$ & t value & p value & significance \\
\hline $\mathrm{ATT} \rightarrow \mathrm{INT}$ & 0.010 & 0.128 & 0.312 & 0.076 & 0.302 & 2.047 & 0.040 & $* *$ \\
$\mathrm{SN} \rightarrow \mathrm{INT}$ & 0.812 & 0.108 & 0.442 & 0.072 & 0.370 & 2.867 & 0.005 & $* *$ \\
$\mathrm{PBC} \rightarrow \mathrm{INT}$ & 0.095 & 0.113 & 0.245 & 0.064 & 0.150 & 1.164 & 0.256 & $\mathrm{NS}$ \\
\hline
\end{tabular}

Note. $p^{(1)}$ and $p^{(2)}$ are path coefficients for Groups 1 and 2, respectively.

$s e^{(1)}$ and $s e^{(2)}$ are standard errors of $p^{(1)}$ and, $p^{(2)}$, respectively.

$* \mathrm{p}<.1, * * \mathrm{p}<.05, * * * \mathrm{p}<.01, \mathrm{NS}$ : not significant.

To verify the predictive accuracy of the model, the SmartPLS blindfolding procedure was used to obtain $\mathrm{Q}^{2}$ values of all intrinsic latent variables of the model, as summarized in Table 7. The $\mathrm{Q}^{2}$ values of all intrinsic latent variables, including intention and all three direct antecedents of intention, are greater than zero, suggesting that the TPB applied in this study has predictive relevance in the EV adoption context. The effect sizes of $\mathrm{f}^{2}$ and $\mathrm{q}^{2}$ were obtained (Table 8) to examine the relative predictive and explanatory effects of the three determinants of TPB. The effect size $\mathrm{f}^{2}$ measures a predictor variable's contribution to a dependent variable's $\mathrm{R}^{2}$ value as a relative indicator of explanatory relevance, and the effect size $\mathrm{q}^{2}$ measures a predictor variable's contribution to a dependent variable's $Q^{2}$ value as a relative indicator of predictive relevance. In general, values of $0.02,0.15$, and 0.35 for both $\mathrm{f}^{2}$ and $\mathrm{q}^{2}$ represent low, medium, and high effects (Hair et al., 2017). Results reveal that social norm has high explanatory and predictive relevance, while attitude and behavioral control have comparatively low relevance on intention for EV adoption.

Table 7. R2 and Q2 values

\begin{tabular}{lll}
\hline Intrinsic latent variables & $\mathrm{R}^{2}$ & $\mathrm{Q}^{2}$ \\
\hline ATT & 0.531 & 0.399 \\
INT & 0.734 & 0.650 \\
\hline
\end{tabular}


Table 8. f2 and q2 effect sizes for the determinants of intention

\begin{tabular}{lll}
\hline Determinants of intention & $\mathrm{f}^{2}$ Effect size & $\mathrm{q}^{2}$ Effect size \\
\hline ATT & 0.111 & 0.060 \\
SN & 0.503 & 0.317 \\
PBC & 0.102 & 0.063 \\
\hline
\end{tabular}

\section{Discussion and Conclusions}

This study examines how consumers' perception of the innovative characteristics of EVs affects their attitudes toward EV adoption and intentions to adopt EVs. A theoretical model integrating TPB (Ajzen, 1991) and DOI (Rogers, 2003) was developed to explain consumer behaviors for the adoption of innovative products in terms of their perception of the innovativeness of the products. This will provide the basis for further research for enhancing EV adoption. The results indicate that all three determinants of TPB have positive effects on intention to adopt EVs. Furthermore, relative advantage, compatibility, and observability positively influence attitude toward EV adoption. Consumer innovativeness functions partly as a moderator between PICs and attitude, i.e., The higher the consumer's innovativeness, the stronger the relationship between compatibility and attitude, and the lower the consumer's innovativeness, the stronger the relationship between relative advantage and attitude. Younger consumers $(20 \mathrm{~s}-30 \mathrm{~s})$ are associated with a stronger relationship between attitude and intention to adopt EVs than older consumers (40s-60s), who are associated with a stronger relationship between subjective norm and intention to adopt EVs.

On the basis of the research results, the following practical implications for promoting demand for EVs are suggested. Among the three determinants of TPB, subjective norm has the greatest impact on the adoption intention of EVs. Groups and societies have a large influence on an individual's behavior (Venkatesh \& Davis, 2000). Social norm has a significant influence on intention (Bamberg, 2003). Therefore, there is a need to activate social networks for sharing information and knowledge of EVs among society, and it is necessary to have a strategy to reduce misunderstanding and dually increase knowledge of EVs by transmitting relevant information using interpersonal media.

PBC for EV adoption is also significant for intentions of EV adoption. The perceived ease and obstacles of EV adoption are essential. Bamberg (2003) revealed that the belief that an individual can control a situation has a large impact on behavioral intention. Thus, the perceived difficulty in adopting EVs acts as a barrier to EV adoption, and hence, a strategy for solving economic and situational factors that impede EV adoption is required such as providing financial benefits (e.g., incentives), purchase subsidies to lower purchasing barriers, or provide information about EVs to lower uncertainties. To this end, an EV company could operate an EV consultation center to provide EV knowledge.

Positive attitude toward EV adoption has a significant effect on adoption intention. Therefore, A need for marketing strategies related to specific PICs, which are important in forming a positive attitude toward EV adoption, prevails. A positive attitude is formed when respondents perceive that adoption of EVs is not much different from that of existing vehicles or when EVs satisfy their desire for a car. EVs are perceived as having a higher relative advantage in terms of economic, technical, and environmental aspects compared to existing vehicles and the more people perceive EVs as observable by others, the more they form a positive attitude toward EV adoption. In contrast, the perceived complexity of EVs and trialability do not significantly affect attitude, with respondents revealing that the use of EV is not difficult or complicated compared to existing vehicles. However, trialability has the highest mean of 3.9 among the five PICs and this implies that respondents consider the possibility of test-driving EVs as important. On the basis of these findings, innovative products such as EVs require marketing strategies that focus on relative benefits, compatibility, and observability.

Creating early market strategies that target people with higher innovativeness (or early adopters) can help promote EV adoption due to early adopters having a more positive attitude toward EV adoption and a higher perception of EV compatibility. After early adopters have spread EVs in the market to some extent, a strategy that emphasizes the relative advantages of electric vehicles over existing vehicles may be more appropriate. In that case, the emphasis of marketing strategies needs to be placed on economic aspects such as fuel economy and tax benefits, technical aspects such as less noise and energy efficiency, and environmental aspects such as less harm to the environment.

The results of analyzing the moderating effect of age on the relationship between intention and its determinants 
demonstrate that, for younger respondents, the relationship between attitude and intention is enhanced, while for older respondents, the relationship between social norm and intention is enhanced. Based on these findings, for the older age group, it is desirable to appeal to them through advertising and providing information through social community networks, while for younger age group it is necessary to focus more on product innovation characteristics that can influence the positive evaluation of EV adoption.

\section{Further Research}

Finally, further research directions are presented. To increase the explanatory and predictive power of the EV adoption model, additional variables other than PICs, such as consumer characteristics (e.g., involvement) and specific product attributes (e.g., price, brand, and vehicle options) should be considered. A comparative study of the characteristics between EV adopters and non-adopters should be conducted.

\section{References}

Agarwal, R., \& Prasad, J. (1997). The role of innovation characteristics and perceived voluntariness in the acceptance of information technologies. Decision Sciences, 28(3), 557-582. https://doi.org/10.1111/j.1540-5915.1997.tb01322.x

Ajzen, I. (1988). Attitudes, personality, and behavior. 1988. Milton Keynes: Open University Press Google Scholar.

Ajzen, I. (1991). The theory of planned behavior. Organizational Behavior and Human Decision Processes, 50(2), 179-211. https://doi.org/10.1016/0749-5978(91)90020-T

Ajzen, I. (2019). Constructing a Theory of Planned Behavior Questionnaire. Retrieved from https://www.researchgate.net/publication/235913732_Constructing_a_Theory_of_Planned_Behavior_Quest ionnaire

Adnan, N., Nordin, S. M., Rahman, I., Vasant, P. M., \& Noor, A. (2017). A comprehensive review on theoretical framework-based electric vehicle consumer adoption research. International Journal of Energy Research, 41(3), 317-335. https://doi.org/10.1002/er.3640

Bartels, J., \& Reinders, M. J. (2011). Consumer innovativeness and its correlates: A propositional inventory for future research. Journal of Business Research, 64(6), 601-609. https://doi.org/10.1016/j.jbusres.2010.05.002

Bamberg, S. (2003). How does environmental concern influence specific environmentally related behaviors? A new answer to an old question. Journal of Environmental Psychology, 23(1), 21-32. https://doi.org/10.1016/S0272-4944(02)00078-6

Bockarjova, M., \& Steg, L. (2014). Can Protection Motivation Theory predict pro-environmental behavior? Explaining the adoption of electric vehicles in the Netherlands. Global Environmental Change, 28, 276-288. https://doi.org/10.1016/j.gloenvcha.2014.06.010

Brady, J., \& O'Mahony, M. (2011). Travel to work in Dublin. The potential impacts of electric vehicles on climate change and urban air quality. Transportation Research Part D: Transport and Environment, 16(2), 188-193. https://doi.org/10.1016/j.trd.2010.09.006

Brunsø, K., Scholderer, J., \& Grunert, K. G. (2004). Closing the gap between values and behavior-a meansend theory of lifestyle. Journal of Business Research, 57(6), 665-670. https://doi.org/10.1016/S0148-2963(02)00310-7

Chen, M. F., \& Tung, P. J. (2014). Developing an extended theory of planned behavior model to predict consumers' intention to visit green hotels. International Journal of Hospitality Management, 36, 221-230. https://doi.org/10.1016/j.ijhm.2013.09.006

Chou, C. J., Chen, K. S., \& Wang, Y. Y. (2012). Green practices in the restaurant industry from an innovation adoption perspective: Evidence from Taiwan. International Journal of Hospitality Management, 31(3), 703-711. https://doi.org/10.1016/j.ijhm.2011.09.006

Crespo, Á. H., \& del Bosque, I. R. (2008). The effect of innovativeness on the adoption of B2C e-commerce: A model based on the Theory of Planned Behaviour. Computers in Human Behavior, 24(6), 2830-2847. https://doi.org/10.1016/j.chb.2008.04.008

Damanpour, F., \& Schneider, M. (2008). Characteristics of innovation and innovation adoption in public organizations: Assessing the role of managers. Journal of Public Administration Research and Theory, 19(3), 495-522. https://doi.org/10.1093/jopart/mun021 
Delang, C. O., \& Cheng, W. T. (2012). Consumers' attitudes towards electric cars: A case study of Hong Kong. Transportation Research Part D: Transport and Environment, 17(6), 492-494. https://doi.org/10.1016/j.trd.2012.04.004

De Groot, J., \& Steg, L. (2007). General beliefs and the theory of planned behavior: The role of environmental concerns in the TPB. Journal of Applied Social Psychology, 37(8), 1817-1836. https://doi.org/10.1111/j.1559-1816.2007.00239.x

Driessen, P. H., \& Hillebrand, B. (2002). Adoption and diffusion of green innovations. Marketing for Sustainability: Towards Transactional Policy-making, 343-355.

Egbue, O., \& Long, S. (2012). Barriers to widespread adoption of electric vehicles: An analysis of consumer attitudes and perceptions. Energy Policy, 48, 717-729.

Environmental Protection Agency, (2015). Overview of air pollution from transportation. Retrieved from https://www.epa.gov/transportation-air-pollution-and-climate-change/learn-about-air-pollution-transportatio $\mathrm{n}$

Fang, J., Shao, P., \& Lan, G. (2009). Effects of innovativeness and trust on web survey participation. Computers in Human Behavior, 25(1), 144-152. https://doi.org/10.1016/j.chb.2008.08.002

Fishbein, M., \& Ajzen, I. (1975). Belief, Attitude, Intention, and Behavior: An Introduction to Theory and Research. Addison-Wesley, Reading, MA.

Frambach, R. T., \& Schillewaert, N. (2002). Organizational innovation adoption: A multi-level framework of determinants and opportunities for future research. Journal of Business Research, 55(2), 163-176. https://doi.org/10.1016/S0148-2963(00)00152-1

Hair Jr, J. F., Hult, G. T. M., Ringle, C., \& Sarstedt, M. (2017). A primer on partial least squares structural equation modeling (2nd ed.). Sage publications, LA. https://doi.org/10.15358/9783800653614

Han, H., Hsu, L. T. J., \& Sheu, C. (2010). Application of the theory of planned behavior to green hotel choice: Testing the effect of environmental friendly activities. Tourism Management, 31(3), 325-334. https://doi.org/10.1016/j.tourman.2009.03.013

Hansen, T. (2008). Consumer values, the theory of planned behaviour and online grocery shopping. $\begin{array}{lllll}\text { International Journal of } & \text { Consumer } & \text { Studies, } & 32(2), & 128-137 .\end{array}$ https://doi.org/10.1111/j.1470-6431.2007.00655.x

Hebert, M., \& Benbasat, I. (1994). Adopting information technology in hospitals: the relationship between attitudes/expectations and behavior. Journal of Healthcare Management, 39(3), 369.

Heffner, R. R., Kurani, K. S., \& Turrentine, T. S. (2007). Symbolism in California's early market for hybrid electric vehicles. Transportation Research Part D: Transport and Environment, 12(6), 396-413. https://doi.org/10.1016/j.trd.2007.04.003

Hidrue, M. K., Parsons, G. R., Kempton, W., \& Gardner, M. P. (2011). Willingness to pay for electric vehicles and their attributes. Resource and Energy Economics, 33(3), 686-705. https://doi.org/10.1016/j.reseneeco.2011.02.002

Holak, S. L., \& Lehmann, D. R. (1990). Purchase intentions and the dimensions of innovation: An exploratory model. Journal of Product Innovation Management: an international publication of the product development \& management association, 7(1), 59-73. https://doi.org/10.1111/1540-5885.710059

Jackson, J. D., Mun, Y. Y., \& Park, J. S. (2013). An empirical test of three mediation models for the relationship between personal innovativeness and user acceptance of technology. Information \& Management, 50(4), 154-161. https://doi.org/10.1016/j.im.2013.02.006

Jansson, J. (2011). Consumer eco-innovation adoption: assessing attitudinal factors and perceived product characteristics. Business Strategy and the Environment, 20(3), 192-210. https://doi.org/10.1002/bse.690

Jansson, J., Nordlund, A., \& Westin, K. (2017). Examining drivers of sustainable consumption: The influence of norms and opinion leadership on electric vehicle adoption in Sweden. Journal of Cleaner Production, 154, 176-187.

Keith, K., \& McWilliams, A. (1999). The returns to mobility and job search by gender. ILR Review, 52(3), 460-477. https://doi.org/10.1177/001979399905200306

Kim, K. J. (2016). Hyundai's Ionic electric car captivated early adopters of 30s. Retrieved from 
http://news.zum.com/articles/33507863. Accessed 25 January 2020

Korea Ministry of Environment. (2019). Status of Electric Vehicle Purchasing Subsidies. Retrieved from https://www.ev.or.kr/portal/localInfo?pMENUMST_ID=21714. Accessed 25 January 2020

Larson, P. D., Viáfara, J., Parsons, R. V., \& Elias, A. (2014). Consumer attitudes about electric cars: Pricing analysis and policy implications. Transportation Research Part A: Policy and Practice, 69, 299-314. https://doi.org/10.1016/j.tra.2014.09.002

Liao, F., Molin, E., \& Van Wee, B. (2017). Consumer preferences for electric vehicles: a literature review. Transport Reviews, 37(3), 252-275. https://doi.org/10.1080/01441647.2016.1230794

López-Mosquera, N., \& Sánchez, M. (2012). Theory of planned behavior and the value-belief-norm theory explaining willingness to pay for a suburban park. Journal of environmental management, 113, 251-262. https://doi.org/10.1016/j.jenvman.2012.08.029

Lowe, B., \& Alpert, F. (2015). Forecasting consumer perception of innovativeness. Technovation, 45, 1-14. https://doi.org/10.1016/j.technovation.2015.02.001

Lu, J., Yao, J. E., \& Yu, C. S. (2005). Personal innovativeness, social influences and adoption of wireless Internet services via mobile technology. The Journal of Strategic Information Systems, 14(3), 245-268. https://doi.org/10.1016/j.jsis.2005.07.003

Marcati, A., Guido, G., \& Peluso, A. M. (2008). The role of SME entrepreneurs' innovativeness and personality in the adoption of innovations. Research Policy, 37(9), 1579-1590. https://doi.org/10.1016/j.respol.2008.06.004

Martin, M. H. (2003). Factors influencing faculty adoption of web-based courses in teacher education programs within the State University of New York (Doctoral dissertation, Virginia Tech).

McKenzie, J. (2001). Head of the class: How teachers learn technology best. American School Board Journal, $188(1), 20-23$.

Morton, C., Anable, J., \& Nelson, J. D. (2016). Exploring consumer preferences towards electric vehicles: The influence of consumer innovativeness. Research in Transportation Business \& Management, 18, 18-28. https://doi.org/10.1016/j.rtbm.2016.01.007

Olshavsky, R. W., \& Spreng, R. A. (1996). An exploratory study of the innovation evaluation process. Journal of Product Innovation Management, 13(6), 512-529.

Orlov, A., \& Kallbekken, S. (2019). The impact of consumer attitudes towards energy efficiency on car choice: Survey results from Norway. Journal of Cleaner Production, 214, 816-822. https://doi.org/10.1016/j.jclepro.2018.12.326

Parisot, A. H. (1997). Distance education as a catalyst for changing teaching in the community college: Implications for institutional policy. New Directions for Community Colleges, (99), 5-13. https://doi.org/10.1002/cc.9901

Putzer, G. J., \& Park, Y. (2012). Are physicians likely to adopt emerging mobile technologies? Attitudes and innovation factors affecting smartphone use in the Southeastern United States. Perspectives in Health Information Management/AHIMA, American Health Information Management Association, 9(Spring).

Plötz, P., Schneider, U., Globisch, J., \& Dütschke, E. (2014). Who will buy electric vehicles? Identifying early adopters in Germany. Transportation Research Part A: Policy and Practice, 67, 96-109. https://doi.org/10.1016/j.tra.2014.06.006

Rezvani, Z., Jansson, J., \& Bodin, J. (2015). Advances in consumer electric vehicle adoption research: A review and research agenda. Transportation Research part D: Transport and Environment, 34, 122-136. https://doi.org/10.1016/j.trd.2014.10.010

Roehrich, G. (2004). Consumer innovativeness: Concepts and measurements. Journal of Business Research, 57(6), 671-677. https://doi.org/10.1016/S0148-2963(02)00311-9

Rogers, E. M. (2003). Diffusion of Innovations (5 ${ }^{\text {th }}$ ed.). The Free Press, NY, pp. 15-17.

Schuitema, G., Anable, J., Skippon, S., \& Kinnear, N. (2013). The role of instrumental, hedonic and symbolic attributes in the intention to adopt electric vehicles. Transportation Research Part A: Policy and Practice, 48, 39-49. https://doi.org/10.1016/j.tra.2012.10.004

Smerecnik, K. R., \& Andersen, P. A. (2011). The diffusion of environmental sustainability innovations in North 
American hotels and ski resorts. Journal of Sustainable Tourism, 19(2), 171-196. https://doi.org/10.1080/09669582.2010.517316

Sutcliffe, M., Hooper, P., \& Howell, R. (2008). Can eco-footprinting analysis be used successfully to encourage more sustainable behaviour at the household level?. Sustainable Development, 16(1), 1-16. https://doi.org/10.1080/09669582.2010.517316

Taylor, S., \& Todd, P. A. (1995). Understanding information technology usage: A test of competing models. Information Systems Research, 6(2), 144-176. https://doi.org/10.1287/isre.6.2.144

Van Hooft, E. A., Born, M. P., Taris, T. W., \& van der Flier, H. (2005). Predictors and outcomes of job search behavior: The moderating effects of gender and family situation. Journal of Vocational Behavior, 67(2), 133-152. https://doi.org/10.1016/j.jvb.2004.11.005

Venkatesh, V., \& Davis, F. D. (2000). A theoretical extension of the technology acceptance model: Four $\begin{array}{lllll}\text { longitudinal field } & \text { studies. } & \text { Management } & \text { Science, } & \text { 46(2), }\end{array}$ https://doi.org/10.1287/mnsc.46.2.186.11926

Venkatesh, V., Morris, M. G., Davis, G. B., \& Davis, F. D. (2003). User acceptance of information technology: Toward a unified view. MIS Quarterly, 425-478. https://doi.org/10.2307/30036540

Wang, S., Fan, J., Zhao, D., Yang, S., \& Fu, Y. (2016). Predicting consumers' intention to adopt hybrid electric vehicles: using an extended version of the theory of planned behavior model. Transportation, 43(1), 123-143. https://doi.org/10.1007/s11116-014-9567-9

White, L. V., \& Sintov, N. D. (2017). You are what you drive: Environmentalist and social innovator symbolism drives electric vehicle adoption intentions. Transportation Research Part A: Policy and Practice, 99, 94-113. https://doi.org/10.1016/j.tra.2017.03.008

Yadav, R., Balaji, M. S., \& Jebarajakirthy, C. (2019). How psychological and contextual factors contribute to travelers' propensity to choose green hotels?. International Journal of Hospitality Management, 77, 385-395. https://doi.org/10.1016/j.ijhm.2018.08.002

Yang, K. (2012). Consumer technology traits in determining mobile shopping adoption: An application of the extended theory of planned behavior. Journal of Retailing and Consumer Services, 19(5), 484-491. https://doi.org/10.1016/j.jretconser.2012.06.003

Zhou, Y., Thøgersen, J., Ruan, Y., \& Huang, G. (2013). The moderating role of human values in planned behavior: the case of Chinese consumers' intention to buy organic food. Journal of Consumer Marketing, 30(4), 335-344. https://doi.org/10.1108/JCM-02-2013-0482

\section{Appendix 1.}

Questionnaire items

\begin{tabular}{ll}
\hline Construct & Measurement items \\
\hline Consumer innovativeness \\
INN1 & If I hear about a new information technology, I would look for ways to experiment with it. \\
INN2 & Among my peers, I am usually the first to explore new information technologies. \\
INN3 & I like to experiment with new information technologies. \\
INN4 & In general, I am hesitant to try out new information technologies. (R) \\
Perceived innovation characteristics \\
RA1 & An electric car's use would decrease my fossil fuels and $\mathrm{CO}_{2}$ emissions. \\
RA2 & Buying an electric car would be financially advantageous for me. \\
RA3 & An electric car is better than other competitive alternatives. \\
RA4 & An electric car replaces a vastly inferior alternatives \\
COMPAT1 & Using an electric car is in line with my everyday life. \\
COMPAT2 & It is easy to find electric car charging stations. \\
COMPAT3 & Using an electric car is in line with my values. \\
\hline
\end{tabular}




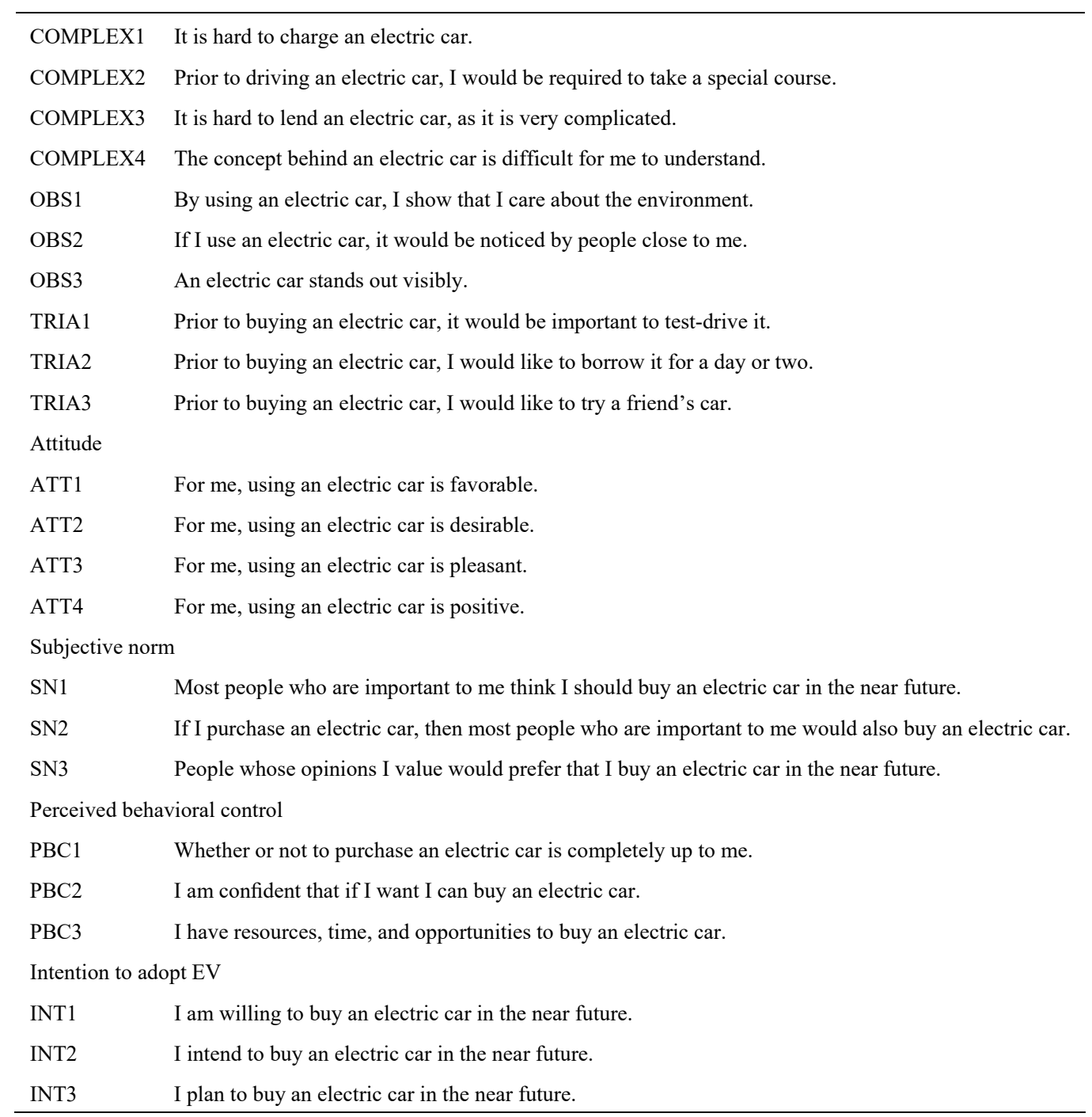

\section{Copyrights}

Copyright for this article is retained by the author(s), with first publication rights granted to the journal.

This is an open-access article distributed under the terms and conditions of the Creative Commons Attribution license (http://creativecommons.org/licenses/by/4.0/). 